\title{
TGF $\beta 1$ and HGF protein secretion by esophageal squamous epithelial cells and stromal fibroblasts in oesophageal carcinogenesis
}

\author{
ZHIBIN XU ${ }^{1}$, SHIJIE WANG ${ }^{1}$, MINGLI WU ${ }^{1}$, WEIWEI ZENG ${ }^{1}$, \\ $\mathrm{XIAOLING} \mathrm{WANG}^{2}$ and ZHIMING DONG ${ }^{3}$ \\ Departments of ${ }^{1}$ Endoscopy, ${ }^{2}$ Pathology and ${ }^{3}$ Molecular Biology, The Fourth Hospital of Hebei Medical University, \\ Shijiazhuang, Hebei 050011, P.R. China
}

Received January 20, 2013; Accepted May 30, 2013

DOI: $10.3892 / 01.2013 .1409$

\begin{abstract}
Esophageal squamous cell carcinoma (ESCC) is an aggressive cancer with a poor prognosis. Cancer-associated fibroblasts (CAFs) affect tumorigenesis by creating an environment primed for growth and invasion through the secretion of factors, including hepatocyte growth factor (HGF) and transforming growth factor $\beta 1$ (TGF $\beta 1$ ). In the present study, the levels of $\alpha$-smooth muscle actin ( $\alpha$-SMA), TGF $\beta 1$ and HGF were determined immunohistochemically in oesophageal precancerous lesions (low- and high-grade intraepithelial neoplasia; LGIEN and HGIEN, respectively), carcinoma in situ (CIS) and squamous cell carcinoma (SCC). Immunoreactivity was observed in the cytoplasm of oesophageal epithelial cells and stromal fibroblasts. Expression levels of $\alpha$-SMA, TGF $\beta 1$ and HGF increased significantly in the following order: normal, LGIEN, HGIEN, CIS and SCC. In addition, linear correlations between the expression of $\alpha$-SMA, TGF $\beta 1$ and HGF and different lesions were observed. Microvessel density (MVD) was measured in all specimens and increased gradually in the normal, LGIEN, HGIEN, CIS and SCC specimens, successively. A linear correlation between MVD and pathological grade was also observed and the MVD in $\alpha$-SMA-, HGF- and TGF 31 -positive groups was higher when compared with that of their negative counterparts. The results of the present study indicated that the frequent overexpression of TGF $\beta 1$ and HGF proteins, secreted by oesophageal epithelium and stromal fibroblasts, promoted the progression of oesophageal precancerous lesions via the proliferation of
\end{abstract}

Correspondence to: Professor Shijie Wang, Department of Endoscopy, The Fourth Hospital of Hebei Medical University, 12 Jiankang Road, Shijiazhuang, Hebei 050011, P.R. China

E-mail: xzblxh@yahoo.com.cn

Key words: esophageal squamous cell carcinoma, fibroblast, transforming growth factor- $\beta 1, \alpha$-smooth muscle actin, hepatocyte growth factor epithelial cells and angiogenesis, through the upregulation of vascular endothelial growth factor (VEGF) expression.

\section{Introduction}

Oesophageal carcinoma is the fourth most common type of malignant carcinoma and has a high mortality rate in China (1). Despite long-term studies, understanding of the molecular changes underlying oesophageal carcinoma is limited. Previous studies have hypothesised that tumourigenesis represents an independent process governed by genes carried by tumour cells $(2,3)$. However, further studies have demonstrated that carcinoma behaviour is also affected by the tumour microenvironment, including the extracellular matrix, blood vasculature, inflammatory cells and myofibroblasts (4). Notably, among these components, cancer-associated fibroblasts (CAFs) play a predominant role in carcinogenesis (5). The activation of CAFs correlates with the expression of $\alpha$-smooth muscle actin ( $\alpha$-SMA), which is the most commonly used marker for CAFs $(6,7)$. Numerous families of growth factors secreted by cancer cells and CAFs are involved in carcinoma initiation and progression. Transforming growth factor $\beta$ (TGF $\beta$ ) is capable of regulating the growth, differentiation, migration, adhesion and apoptosis of cells by binding to the TGF $\beta$ receptors (T $\beta R-I$ and -II) (8). Studies have demonstrated that the TGF $\beta 1-S m a d$ signalling pathway is involved in the progression and prognosis of several types of carcinomas, including oesophageal (9), colorectal (10) and gastric (11) carcinoma. Hepatocyte growth factor (HGF) is a multifunctional cytokine produced by tumour cells and myofibroblasts in tumour stroma. HGF exerts multiple functions, including cell proliferation, migration and metastases $(12,13)$, by binding to c-met, a receptor expressed in epithelial cells. The majority of previous studies have analysed TGF $\beta 1(9,14)$ and HGF $(15,16)$ protein expression in oesophageal squamous cell carcinoma (ESCC) but not in precancerous lesions. In addition, few studies have investigated the functional and clinical significance of TGF $\beta 1$ and HGF proteins, secreted by dysplasia epithelial cells, cancer cells and stroma fibroblasts, in oesophageal carcinogenesis. Therefore, the present study aimed to examine the significance of TGF $\beta 1$ and HGF proteins in oesophageal carcinogenesis and angiogenesis. 


\section{Materials and methods}

Tissue collection and processing. A total of 136 patients, 88 males and 48 females, treated at The Fourth Hospital of Hebei Medical University (Hebei, China) between August, 2006 and August, 2010, were enrolled in the current study (mean age, 62 years; range, 46-75 years). Normal oesophageal tissue, obtained from a distance of $>5 \mathrm{~cm}$ between the normal oesophageal tissue and the edge of the cardiac carcinoma, was obtained from patients undergoing cardiac carcinoma resection. Oesophageal precancerous lesions were obtained from patients undergoing endoscopic mucosal resection for oesophageal precancerous lesions, and oesophageal carcinoma specimens were obtained from patients undergoing oesophagectomy surgery. Written informed consent was provided by all participants and the study was approved by the ethics committee of Hebei Medical University. Individuals had not undergone radiotherapy and chemotherapy prior to oesophagectomy or gastrectomy, and tissues were fixed with $85 \%$ alcohol, embedded with paraffin and serially sectioned at $5 \mu \mathrm{m}$. Sections were mounted onto histostick-coated slides (Haimen Experiment Equipment Factory, Jiangsu, China) and four to five adjacent ribbons were collected for haematoxylin and eosin and immunohistochemical staining.

Classification of pathology. In accordance with the Classification of Tumours of the Digestive System established by the World Health Organisation (17), 136 specimens were divided into 5 groups according to tissue type. These included normal, low- and high-grade intraepithelial neoplasia (LGIEN and HGIEN, respectively), carcinoma in situ (CIS) and squamous cell carcinoma (SCC), and comprised 20, 26, 44, 23 and 23 cases, respectively.

Immunohistochemistry (IHC). Paraffin-embedded sections were deparaffinised with xylene and rehydrated. Sections were incubated with $\mathrm{H}_{2} \mathrm{O}_{2}$ (concentration, $3 \%$ ) for $30 \mathrm{~min}$ at room temperature. Sections were immersed in $0.01 \mathrm{M}$ citrate buffer ( $\mathrm{pH} 6.0)$ at $95^{\circ} \mathrm{C}$ for 10 min for antigen retrieval, and then immersed in phosphate-buffered saline (PBS) for $15 \mathrm{~min}$ at room temperature. Following blocking, the sections were incubated at $4^{\circ} \mathrm{C}$ overnight with primary antibodies, including mouse anti-human $\alpha$-SMA monoclonal (1:100), mouse anti-human CD34 monoclonal (1:80; Beijing Zhongshan Jinqiao Biotechnology Co., Ltd., Beijing, China), rabbit anti-human TGF $\beta 1$ polyclonal (1:100; Bioworld Technology Inc., Nanjing, China) and rabbit anti-human HGF polyclonal (1:100; Santa Cruz Biotechnology, Inc,, Santa Cruz, CA, USA) antibodies, and subsequently washed with PBS. Sections were incubated with biotin-conjugated goat anti-mouse or rabbit $\mathrm{IgG}$ at $37^{\circ} \mathrm{C}$ for $1 \mathrm{~h}$, and visualization was achieved with peroxidase-labelled streptavidin-biotin and diaminobenzidine. Slides were subsequently counterstained with Mayer's haematoxylin, dehydrated and mounted.

Interpretation of IHC. Cytoplasmic staining of HGF and TGF $\beta 1$ was scored by the percentage of positive cells $(0,<10 \%$; $1,10-25 \% ; 2,26-50 \%$ and $3,>51 \%$ ), where 0 was classified as negative expression (-) and 1-3 was classified as positive expression (+). A specimen of invasive breast and hepatic carcinoma served as a positive control for TGF $\beta 1$ and HGF, respectively. Absence of $\alpha$-SMA immunostaining in the myofibroblasts was classified as negative (-) and immunostaining patterns, including focal or diffuse, weak or strong, were classified as positive (+).

Anti-CD34 antibody was used to stain endothelial cells and detect microvessel density (MVD), as described previously (18). A single endothelial cell or cluster of endothelial cells, with or without a lumen, was hypothesised to represent individual vessels. However, vessels with thick muscular walls or of a caliber of $>8$ red blood cells were excluded. Highly vascular areas were identified by scanning sections at low power magnification (x100) to determine three hot spots. The MVD is presented as the mean of the highest three counts at high power magnification (x200), and the slides were interpreted by two independent observers (Xiaoling Wang and Zhiming Dong).

Statistical analysis. Results were analysed using SPSS software, version 13.0 (SPSS, Inc., Chicago, IL, USA). Comparison of the expression of $\alpha$-SMA, TGF $\beta 1$ and HGF among various clinical and histological parameters was performed using the Pearson's $\chi^{2}$ test and the Fisher's exact test. Correlations among the various factors were analysed using the Spearman's rank correlation and values of MVD were analysed with analysis of variance and Dunnett's tests. Data are presented as the mean \pm standard deviation. A two-sided $\mathrm{P}<0.05$ was considered to indicate a statistically significant difference.

\section{Results}

Stromal fibroblast expression of $\alpha$-SMA in oesophageal carcinogenesis. The IHC results showed ascending rates of stromal fibroblast expression of $\alpha$-SMA in oesophageal carcinogenesis. The majority of $\alpha$-SMA-positive fibroblasts were distributed in the oesophageal stroma surrounding cancer nests or adjacent to dysplasia cells (Fig. 1). No significant differences were identified between the positive rates of $\alpha$-SMA expression with respect to gender and age. The positive rates of $\alpha$-SMA expression in the HGIEN, CIS and SCC groups were statistically significant when compared with that of the normal group; however, no significant difference in $\alpha$-SMA expression rates was identified between the LGIEN and normal groups.

Expression of TGF 1 and HGF in oesophageal carcinogenesis. The majority of TGF $\beta 1$ and HGF expression was localised in the cytoplasm of tumour and dysplasia cells, and positive cells were distributed in the proliferative basal cell zone. In the ESCC tissues, positive staining of TGF $\beta 1$ and HGF was observed in stromal fibroblasts and inflammatory cells adjacent to tumour cells, particularly at the invasive edges of tumours (Figs. 2 and 3). Ascending positive expression levels of TGF $\beta 1$ and HGF were observed in oesophageal carcinogenesis. The positive immunostaining rate for TGF $\beta 1$ and HGF was low in the normal group but increased progressively from LGIEN to HGIEN, CIS and SCC groups, successively (Table I). A significant difference in TGF $\beta 1$ and HGF expression was observed between the normal epithelia and the epithelia of LGIEN, HGIEN, CIS and SCC (with the exception of LGIEN for HGF). TGF $\beta 1$ and HGF expression exhibited a linear correlation with 
Table I. Expression of $\alpha$-SMA, TGF $\beta 1$ and HGF at various clinical and histological parameters.

\begin{tabular}{|c|c|c|c|c|c|c|c|}
\hline \multirow[b]{2}{*}{ Characteristic } & \multirow[b]{2}{*}{$\mathrm{n}$} & \multicolumn{2}{|c|}{$\alpha-\mathrm{SMA}$} & \multicolumn{2}{|c|}{ TGF $\beta 1$} & \multicolumn{2}{|c|}{ HGF } \\
\hline & & $\mathrm{n}(\%)$ & $\mathrm{P}$-value & $\mathrm{n}(\%)$ & P-value & $\mathrm{n}(\%)$ & P-value \\
\hline \multicolumn{8}{|l|}{ Gender } \\
\hline Male & 88 & $40(45.5)$ & & $46(52.3)$ & & $28(31.8)$ & \\
\hline Female & 48 & 19 (39.6) & 0.509 & $32(66.7)$ & 0.105 & $8(16.7)$ & 0.056 \\
\hline \multicolumn{8}{|l|}{ Age, years } \\
\hline$<60$ & 61 & $26(42.6)$ & & $36(59.0)$ & & $16(26.2)$ & \\
\hline$\geq 60$ & 75 & $33(42.7)$ & 0.872 & $42(56.0)$ & 0.724 & $20(26.7)$ & 0.954 \\
\hline \multicolumn{8}{|c|}{ Histological type } \\
\hline NM & 20 & $0(0.0)$ & & $1(5.0)$ & & $0(0.0)$ & \\
\hline LGIEN & 26 & $3(11.5)$ & $0.246^{\mathrm{a}}$ & $15(57.7)$ & $0.000^{\mathrm{a}}$ & $1(3.8)$ & $0.375^{\mathrm{a}}$ \\
\hline HGIEN & 44 & $18(40.9)$ & $0.001^{\mathrm{a}}$ & $29(65.9)$ & $0.000^{\mathrm{a}}$ & $13(29.5)$ & $0.006^{\mathrm{a}}$ \\
\hline CIS & 23 & $15(65.2)$ & $0.000^{\mathrm{a}}$ & $16(69.6)$ & $0.000^{\mathrm{a}}$ & $9(39.1)$ & $0.002^{\mathrm{a}}$ \\
\hline $\mathrm{SCC}$ & 23 & $23(100.0)$ & $0.000^{\mathrm{a}}$ & $17(70.0)$ & $0.000^{\mathrm{a}}$ & $13(56.5)$ & $0.000^{\mathrm{a}}$ \\
\hline
\end{tabular}

${ }^{a}$ Compared with NM. $\alpha$-SMA, $\alpha$-smooth muscle actin; TGF $\beta 1$, transforming growth factor $\beta 1$; HGF, hepatocyte growth factor; NM, normal; LGIEN, low-grade intraepithelial neoplasia; HGIEN, high-grade intraepithelial neoplasia; CIS, carcinoma in situ; SCC, squamous cell carcinoma.

Table II. Correlation between $\alpha$-SMA and TGF $\beta 1$ protein expression.

\begin{tabular}{lcccc}
\hline & \multicolumn{2}{c}{ TGF $\beta 1$} & & \\
\cline { 2 - 3 }$\alpha$-SMA & - & + & & r \\
\hline- & 45 & 32 & & P-value \\
+ & 13 & 46 & 0.365 & $0.000^{\mathrm{a}}$ \\
\hline
\end{tabular}

${ }^{\mathrm{a}} \mathrm{P}<0.05$, vs. correlation coefficient. $\alpha$-SMA, $\alpha$-smooth muscle actin; TGF $\beta 1$, transforming growth factor $\beta 1$.

the progression of the various lesions $(\mathrm{P}<0.05)$. The values of TGF $\beta 1$ and HGF linear correlations with various lesions were -0.356 and -0.437 , respectively.

No significant differences were identified between TGF $\beta 1$ and HGF expression with respect to gender and age. However, a significant difference was identified in TGF $\beta 1$ and HGF expression in ESCC and each stage of oesophageal precancerous lesions when compared with that in the normal group.

Correlation between $\alpha$-SMA and TGF $\beta 1$ expression in oesophageal carcinogenesis. The frequency of TGF $\beta 1$ overexpression was higher in $\alpha$-SMA-positive groups when compared with that of the $\alpha$-SMA-negative groups. The correlation between $\alpha$-SMA and TGF $\beta 1$ was positive and statistically significant [correlation coefficient (r), 0.365; P=0.000; Table II].

MVD among various clinical and histological parameters. No significant differences in the MVD were identified with regard to gender and age. The MVD was $12.3 \pm 1.6,15.7 \pm 1.9$, $20.9 \pm 2.2,21.4 \pm 1.9$ and $22.0 \pm 2.3$ in the normal, LGIEN,
Table III. MVD at various clinical and histological parameters.

\begin{tabular}{|c|c|c|c|}
\hline Characteristic & $\mathrm{n}$ & MVD & $\mathrm{P}$-value \\
\hline \multicolumn{4}{|l|}{ Gender } \\
\hline Male & 88 & $21.2 \pm 3.5$ & \\
\hline Female & 48 & $20.8 \pm 3.8$ & 0.755 \\
\hline \multicolumn{4}{|l|}{ Age, years } \\
\hline$\geq 60$ & 75 & $21.2 \pm 3.4$ & \\
\hline$<60$ & 61 & $22.0 \pm 3.1$ & 0.886 \\
\hline \multicolumn{4}{|c|}{ Pathological grade } \\
\hline Normal & 20 & $12.3 \pm 1.6$ & \\
\hline LGIEN & 26 & $15.7 \pm 1.9^{\mathrm{a}}$ & $0.041^{\mathrm{a}}$ \\
\hline HGIEN & 44 & $20.9 \pm 2.2^{\mathrm{a}, \mathrm{b}}$ & $0.012^{\mathrm{a}}$ \\
\hline CIS & 23 & $21.4 \pm 1.9^{\mathrm{a}, \mathrm{b}, \mathrm{c}}$ & $0.009^{\mathrm{a}}$ \\
\hline SCC & 23 & $22.0 \pm 2.3^{\mathrm{a}, \mathrm{b}, \mathrm{c}}$ & $0.005^{\mathrm{a}}$ \\
\hline \multicolumn{4}{|l|}{$\alpha-\mathrm{SMA}$} \\
\hline- & 77 & $15.3 \pm 7.3$ & \\
\hline+ & 59 & $22.8 \pm 5.6$ & 0.044 \\
\hline \multicolumn{4}{|l|}{ TGF $\beta 1$} \\
\hline- & 58 & $15.6 \pm 4.9$ & \\
\hline+ & 78 & $20.9 \pm 4.6$ & 0.047 \\
\hline \multicolumn{4}{|l|}{$\mathrm{HGF}$} \\
\hline- & 100 & $15.2 \pm 3.3$ & \\
\hline+ & 36 & $28.3 \pm 5.8$ & 0.008 \\
\hline
\end{tabular}

${ }^{\mathrm{a}} \mathrm{P}<0.05$, vs. NM; ${ }^{\text {}} \mathrm{P}<0.05$ vs. LGIEN; ${ }^{\mathrm{c}} \mathrm{P}<0.05$ vs. HGIEN. MVD, microvessel density; NM, normal; LGIEN, low-grade intraepithelial neoplasia; HGIEN, high-grade intraepithelial neoplasia; CIS, carcinoma in situ; SCC, squamous cell carcinoma; $\alpha$-SMA, $\alpha$-smooth muscle actin; TGF $\beta 1$, transforming growth factor $\beta 1$; HGF, hepatocyte growth factor. 


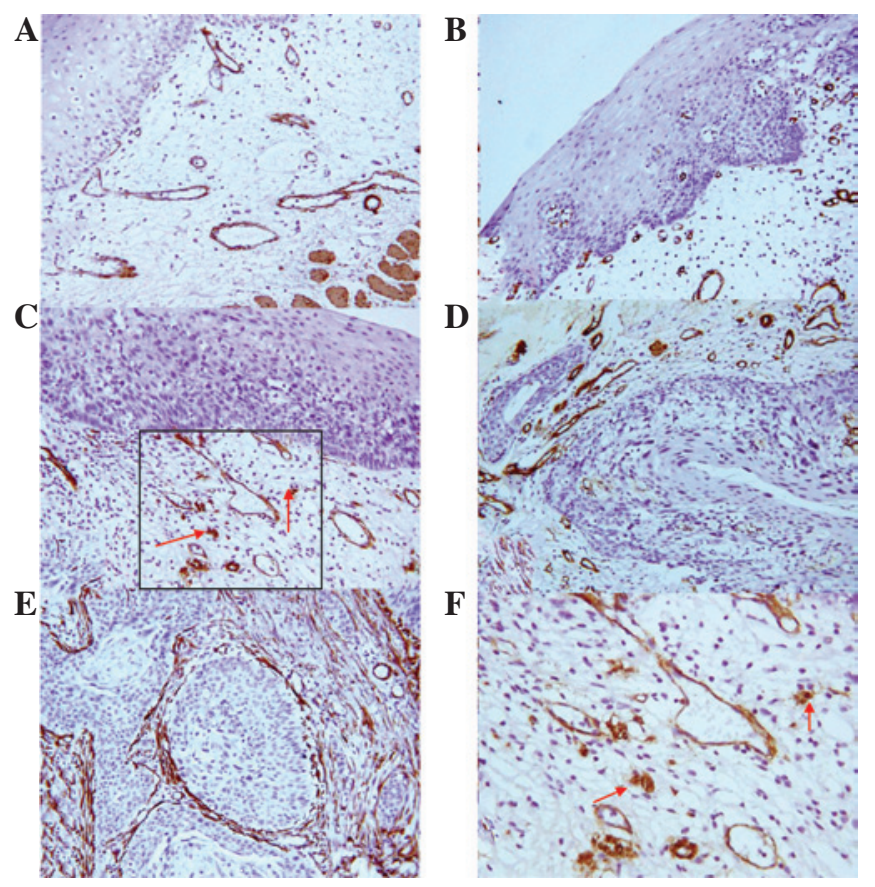

Figure 1. Expression of $\alpha$-SMA in stromal fibroblasts in esophageal carcinogenesis. (A and B) $\alpha$-SMA-negative NM and LGIEN tissues, respectively (SP staining; magnification, x200). (C-E) $\alpha$-SMA-positive expression in HGIEN, CIS and SCC tissues, respectively (SP staining; magnification, $\mathrm{x} 200$ ). (F) Magnification of Fig. 1C (SP staining; magnification, x400). Red arrows indicate myofibroblast staining. $\alpha$-SMA, $\alpha$-smooth muscle actin; NM, normal; LGIEN, low-grade intraepithelial neoplasia; HGIEN, high-grade intraepithelial neoplasia; CIS, carcinoma in situ; SCC, squamous cell carcinoma; SP, streptavidin-peroxidase.
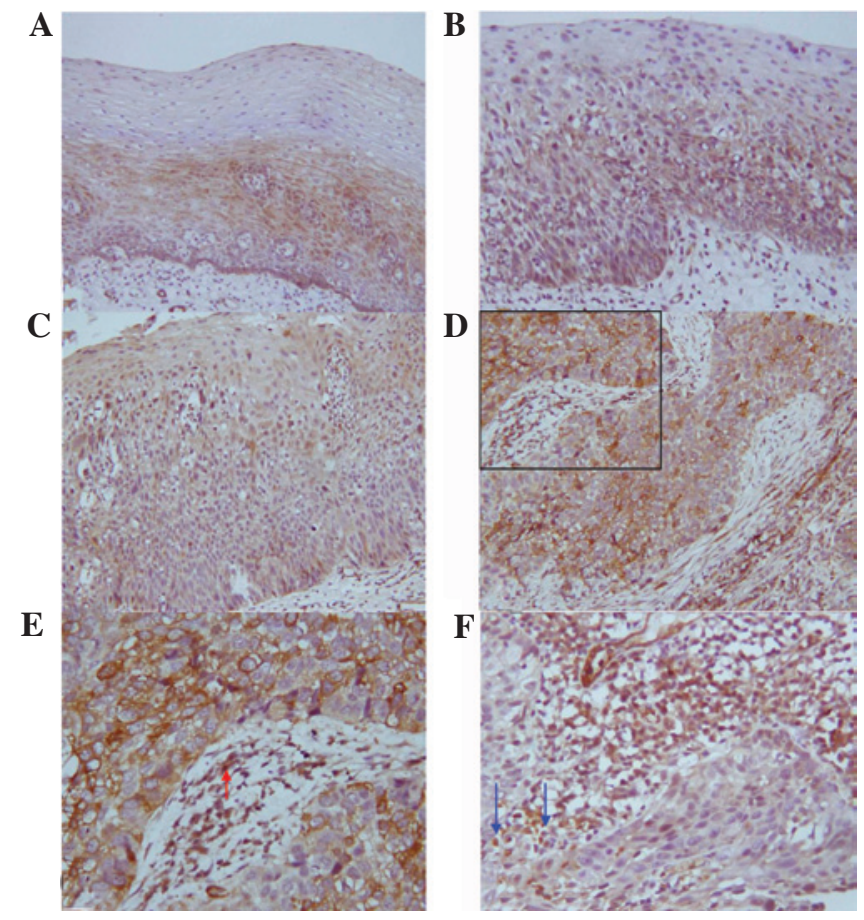

Figure 2. Expression of TGF $\beta 1$ in esophageal carcinogenesis (A-D) TGF 1 1-positive LGIEN, HGIEN, CIS and SCC tissues, respectively (SP staining; magnification, $\mathrm{x} 200$ ). ( $\mathrm{E}$ and F) TGF 31 -positive expression in myofibroblasts (red arrows) and inflammatory cells (blue arrows) (SP staining; magnification, $\mathrm{x} 400)$. TGF $\beta 1$, transforming growth factor $\beta 1$; LGIEN, low-grade intraepithelial neoplasia; HGIEN, high-grade intraepithelial neoplasia; CIS, carcinoma in situ; SCC, squamous cell carcinoma; SP streptavidin-peroxidase
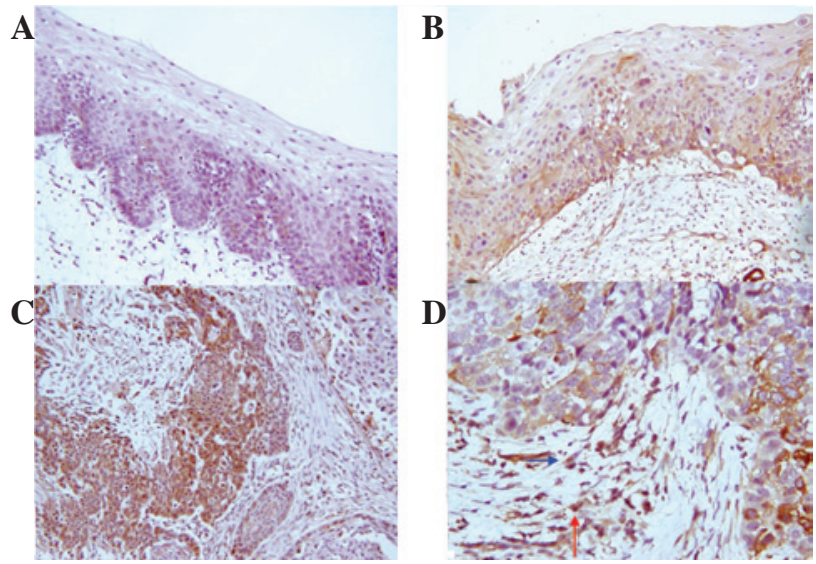

Figure 3. Expression of HGF in esophageal carcinogenesis (A-C) HGF-negative LGIEN, HGIEN and SCC tissues, respectively (SP staining; magnification, x200). (D) HGF-positive stromal myofibroblasts (red arrows) and inflammatory cells (blue arrows) (SP staining; magnification, x400). HGF, hepatocyte growth factor; LGIEN, low-grade intraepithelial neoplasia; HGIEN, high-grade intraepithelial neoplasia; SCC, squamous cell carcinoma; SP, streptavidin-peroxidase.
$\mathbf{A}$
$\mathbf{C}$

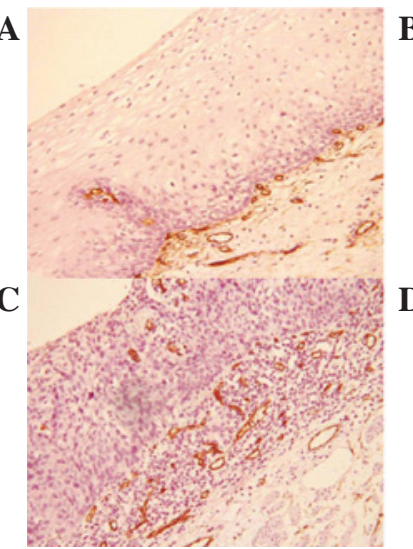

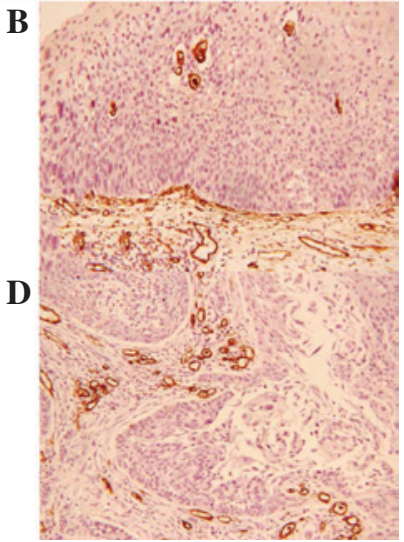

Figure 4. MVD in various esophageal lesions (SP staining; magnification, x200). (A) NM, (B) HGIEN, (C) CIS and (D) invasive SCC. MVD, microvessel density; NM, normal; LGIEN, low-grade intraepithelial neoplasia; HGIEN, high-grade intraepithelial neoplasia; CIS, carcinoma in situ; SCC, squamous cell carcinoma; SP, streptavidin-peroxidase.

HGIEN, CIS and SCC groups, respectively. The higher values of MVD in the HGIEN, CIS and SCC groups were statistically significant when compared with that of the normal and LGIEN groups. $\alpha$-SMA-, HGF- and TGF $\beta 1$-positive groups exhibited significantly higher MVDs when compared with that of their negative counterparts (Table III; Fig. 4).

\section{Discussion}

Activated fibroblasts in tumour stroma are known as CAFs and are commonly identified by the expression of $\alpha$-SMA $(19,20)$. Studies have demonstrated that CAFs are significant promoters of tumour growth and progression via growth factors, including TGF $\beta 1$ and HGF, which are secreted by the CAFs themselves and/or by carcinoma cells (21). In the present study, positive $\alpha$-SMA expression rates increased from LGIEN to HGIEN, CIS and SCC groups, successively. The majority of $\alpha$-SMA was localised to atypical fibroblasts 
(AFs) and CAFs surrounding cancer nests. The expression pattern of $\alpha$-SMA from LGIEN to HGIEN and CIS groups was weak and focal. By contrast, marked and diffuse staining of $\alpha$-SMA was observed in the ESCC tissues, particularly in invasive carcinomas. Of note, overexpression of TGF $\beta 1$ positively correlated with the number of $\alpha$-SMA-positive fibroblasts. Numerous studies (22-25) have demonstrated that TGF $\beta 1$ is capable of inducing $\alpha$-SMA-negative fibroblasts into $\alpha$-SMA-positive fibroblasts. The specific mechanism has been hypothesised to involve TGF $\beta 1$ activation of RhoA, which induces $\alpha$-SMA expression via activation of the endothelial growth factor receptor (26).

Previous studies have demonstrated that overexpression of TGFß1 (27) and HGF (28) is associated with advanced stage oesophageal (Barrett's) adenocarcinoma. However, few studies have analysed the overexpression of TGF $\beta 1$ and HGF in oesophageal squamous cell carcinogenesis. In the present study, carcinoma cells and CAFs surrounding cancer nests markedly expressed TGF $\beta 1$ and HGF in ESCC when compared with that of precancerous lesions, particularly at the invasive edges of the carcinoma. Expression of TGF $\beta 1$ and HGF in inflammatory cells was also shown in regions adjacent to cancer nests. In addition, the positive staining rates of TGF $\beta 1$ and HGF increased significantly in the LGIEN, HGIEN, CIS and SCC groups, when compared with that in the normal group. Thus, the immunoreactivity of TGF $\beta 1$ and HGF occurred during the early stages of oesophageal carcinogenesis. No significant differences were identified between TGF $\beta 1$ and HGF expression in the HGIEN, CIS and SCC groups. However, TGF $\beta 1$ and HGF expression levels showed linear correlations with oesophageal pathological grade. It has been hypothesised that the overexpression of TGF $\beta 1$ and HGF may be involved in hyperproliferation of oesophageal epithelial cells.

Angiogenesis is an essential step for the transition of a small cluster of harmless cells into a large tumour. ESCC is a highly angiogenic tumour and biochemical studies (29) have shown that the TGF $\beta$-vascular endothelial growth factor (VEGF) pathway may induce vascular network formation during fibroblast activation in the ESCC stroma. TGF $\beta 1$ may be associated with gastric tumour progression by indirectly stimulating angiogenesis through the upregulation of VEGF expression (30). In addition, HGF is a significant angiogenic growth factor involved in the progression of $\operatorname{ESCC}(31,32)$. In the current study, the MVD increased rapidly through the normal, LGIEN, HGIEN, CIS and SCC groups, successively. However, no significant differences were identified in the MVD between the HGIEN, CIS and SCC groups. Coexpression of TGF $\beta 1$ and HGF was examined, and the correlations with MVD were evaluated in the 136 specimens. The values of MVD in the LGIEN, HGIEN, CIS and SCC groups with positive TGF $\beta 1$ and HGF expression were higher compared with that in the groups that were negative for TGF $\beta 1$ and HGF (data not shown). The results of the present study have indicated that TGF $\beta 1$ and HGF contribute to oesophageal angiogenesis at the stage of initiation via their respective pathways.

From the results of the present study and previous studies performed in mouse models $(33,34)$, we hypothesise that the suitable microenvironment created by AFs and CAFs in the stroma not only contributes to cancer progression but also to angiogenesis in oesophageal precancerous lesions and carcinoma. In addition, TGF $\beta 1$ and HGF may be important for oesophageal carcinogenesis and angiogenesis.

\section{Acknowledgements}

The authors would like to thank Z. Dong Wang and Y. Jun Wang for their pathological examination and analysis.

\section{References}

1. Wei WQ, Qiao YL, Wang GQ, et al: Progress in prevention and control of esophageal carcinoma in high-risk population. J Pract Oncol 6: 371-373, 2001 (In Chinese)

2. Martin de Civetta MT and Civetta JD: Carcinogenesis. Salud Publica Mex 53: 405-414, 2011 (In Spanish).

3. Weiss RA: Multistage carcinogenesis. Br J Cancer 12: 1981-1982, 2004.

4. Xing F, Saidou J and Watabe K: Cancer associated fibroblasts (CAFs) in tumor microenvironment. Front Biosci 15: 166-179, 2010.

5. Bhowmick NA, Neilson EG and Moses HL: Stromal fibroblasts in cancer initiation and progression. Nature 432: 332-337, 2004.

6. Sugimoto H, Mundel TM, Kieran MW and Kalluri R: Identification of fibroblast heterogeneity in the tumour microenvironment. Cancer Biol Ther 5: 1640-1646, 2006.

7. Erez N, Ttuitt M, Olson P, et al: Cancer-associated fibroblasts are activated in incipient neoplasia to orchestrate tumour-promoting inflammation in an NF-kappaB-dependent manner. Cancer Cell 17: 135-147, 2010

8. Zhang B, Halder SK, Zhang S and Datta PK: Targeting transforming growth factor-beta signaling in liver metastasis of colon cancer. Cancer Lett 277: 114-120, 2009.

9. Gholamin M, Moaven O, Memar B, et al: Overexpression and interactions of interleukin-10, transforming growth factor beta, and vascular endothelial growth factor in esophageal squamous cell carcinoma. World J Surg 33: 1439-1445, 2009.

10. Langenskiöld M, Holmdahl L, Falk P, et al: Increased TGF-beta 1 protein expression in patients with advanced colorectal cancer. J Surg Oncol 97: 409-415, 2008.

11. Hawinkels LJ, Verspaget HW, van Duijn W, et al: Tissue level, activation and cellular localisation of TGF-beta1 and association with survival in gastric cancer patients. Br J Cancer 97: 398-404, 2007.

12. Matsumoto K, Date K, Ohmichi H, et al: Hepatocyte growth factor in lung morphogenesis and tumour invasion: role as a mediator in epithelium-mesenchyme and tumour-stroma interactions. Cancer Chemother Pharmacol 38 (Suppl): S42-S47, 1996.

13. Uchida D, Kawamata H, Omotehara F, et al: Role of HGF/c-met system in invasion and metastasis of oral squamous cell carcinoma cells in vitro and its clinical significance. Int J Cancer 93: 489-496, 2001.

14. Zhou Q, Dong Wang L, Du F, et al: Changes of TGFbeta1 and TGFbetaRII expression in esophageal precancerous and cancerous lesions: a study of a high-risk population in Henan, northern China. Dis Esophagus 15: 74-79, 2002.

15. Ren Y, Cao B, Law S, et al: Hepatocyte growth factor promotes cancer cell migration and angiogenic factors expression: a prognostic marker of human esophageal squamous cell carcinomas. Clin Cancer Res 11: 6190-6197, 2005.

16. Takada N, Yano Y, Matsuda T, et al: Expression of immunoreactive human hepatocyte growth factor in human esophageal squamous cell carcinomas. Cancer Lett 97: 145-148, 1995.

17. Bosman FT, Carneiro F, Hruban RH and Theise ND (eds): World Health Organization Classification of Tumours of the Digestive System. IARC Press, Lyon, 2010.

18. El-Shahat M, Lotfy M, Fahmy L, et al: Prognostic value of microvessel density, matrix metalloproteinase- 9 and p53 protein expression in esophageal cancer. J Egypt Natl Canc Inst 16: 224-230, 2004.

19. Rønnov-Jessen L, Petersen OW and Bissell MJ: Cellular changes involved in conversion of normal to malignant breast: importance of the stromal reaction. Physiol Rev 76: 69-125, 1996.

20. Gabbiani G: The myofibroblast in wound healing and fibrocontractive diseases. J Pathol 200: 500-503, 2003. 
21. Mueller MM and Fusenig NE: Friends or foes-bipolar effects of the tumour stroma in cancer. Nat Rev Cancer 4: 839-849, 2004.

22. Fuyuhiro Y, Yashiro M, Noda S, et al: Upregulation of cancer-associated myofibroblasts by TGF- $\beta$ from scirrhous gastric carcinoma cells. Br J Cancer 105: 996-1001, 2011.

23. Abe R, Donnelly SC, Peng T, et al: Peripheral blood fibrocytes: differentiation pathway and migration to wound sites. J Immunol 166: 7556-7562, 2001.

24. Tuxhorn JA, McAlhany SJ, Yang F, et al: Inhibition of transforming growth factor-beta activity decreases angiogenesis in a human prostate cancer-reactive stroma xenograft model. Cancer Res 62: 6021-6025, 2002.

25. Brenmoehl J, Miller SN, Hofmann C, et al: Transforming growth factor-beta 1 induces intestinal myofibroblast differentiation and modulates their migration. World J Gastroenterol 15: 1431-1442, 2009.

26. Masszi A, Di Ciano C, Sirokmány G, et al: Central role for Rho in TGF-betal-induced alpha-smooth muscle actin expression during epithelial-mesenchymal transition. Am J Physiol Renal Physiol 284: F911-F924,2003.

27. Von Rahden BH, Stein HJ, Feith M, et al: Overexpression of TGF-beta1 in esophageal (Barrett's) adenocarcinoma is associated with advanced stage of disease and poor prognosis. Mol Carcinog 45: 786-794, 2006.

28. Herrera LJ, El-Hefnawy T, Queiroz de Oliveira PE, et al: The HGF receptor c-Met is overexpressed in esophageal adenocarcinoma. Neoplasia 7: 75-84, 2005.
29. Noma K, Smalley KS, Lioni M, et al: The essential role of fibroblasts in esophageal squamous cell carcinoma-induced angiogenesis. Gastroenterology 134: 1981-1993, 2008.

30. Saito H, Tsujitani S, Oka S, et al: The expression of transforming grow th factor-betal is significantly correlated with the expression of vascular endothelial growth factor and poor prognosis of patients with advanced gastric carcinoma. Cancer 86: 1455-1462, 1999.

31. Grugan KD, Miller CG, Yao Y, et al: Fibroblast-secreted hepatocyte growth factor plays a functional role in esophageal squamous cell carcinoma invasion. Proc Natl Acad Sci USA 107: 11026-11031, 2010

32. Oshima Y, Yajima S, Yamazaki K, et al: Angiogenesis-related factors are molecular targets for diagnosis and treatment of patients with esophageal carcinoma. Ann Thorac Cardiovasc Surg 16: 389-393, 2010.

33. Kuperwasser C, Chavarria T, Wu M, et al: Reconstruction of functionally normal and malignant human breast tissues in mice. Proc Natl Acad Sci USA 101: 4966-4971, 2004.

34. Bhowmick NA, Chytilt A, Plieth D, et al: TGF-beta signaling in fibroblasts modulates the oncogenic potential of adjacent epithelia. Science 303: 848-851, 2004. 